\title{
Decision and decision makers
}

\author{
Anuta Porutiu, Babes-Bolyai University, Cluj-Napoca, Romania
}

\begin{abstract}
In the current economic context, decision making requires complex and multiple actions on the part of the policy makers, who are more challenged than in previous situations, due to the crisis that we are facing. Decision problems cannot be solved by focusing on manager's own experience or intuition, but require constant adaptation of the methods used effectively in the past to new challenges.

Thus, a systemic analysis and modeling of arising issues is required, resulting in the stringent use of Decision Support Systems (DSS), as a necessity in a competitive environment. DSS optimize the situation by getting a timely decision because the decision making process must acquire, process and interpret an even larger amount of data in the shortest possible time.

A solution for this purpose is the artificial intelligence systems, in this case Decision Support Systems (DSS), used in a wider area due to expansion of all the new information technologies in decisionmaking processes. These substantial cyber innovations have led to a radical shift in the relationship between enterprise success and quality of decisions made by managers.
\end{abstract}

\section{Keywords}

Decision Support Systems, decision making, decision making process, human resources

\section{JEL Codes: M 10, M 15}

\section{The benefits of DSS in decision making}

In practice managerial decision has two forms: decision-making and decision making process. Decision-making refers to less complex decision situations which are repetitive or in which variables involved are well known by the governor. Decision-making process involves a great consumption of time during which information is collected and analyzed, people are asked to give their opinion in the emerging decision situation. Basically the decision making process consists of a series of stages through which the managerial decision is prepared, adopted, implemented and evaluated.

To drive the achievement of the objectives, management decisions must meet a number of criteria, of which the most important ones are considered the following: scientific validity of the decision. This leads to avoidance of improvisations and subjectivity in making decisions. legality of the decision. The decision should be made only by the person invested with legal right and empowered to do so. Completeness of the decision. The decision must contain all the necessary elements for a correct understanding and implementation. Opportunity of the decision. A good decision taken in due time is better than a very good decision taken late. Efficiency of the decision. The aim is to achieve a good effect following a specific effort. Coordination of the decision. It ensures that decisions on the various departments of the organization are compatible with each other and lead to achievement of the general objective of the whole enterprise.

According to Peter Drucker "Decisions should be made at the lowest possible level, in accordance with their nature, and as close as possible to the place that requires action. Today there is a tendency to do this, and therefore there are systems that assist managers' decisions specific to each management level. 


\section{Elements of decision making}

Decision making is defined as a series of steps starting with the analysis of the information, continues with the selection of several alternatives and assessment of the selected alternative on the problem being investigated.

In any management decision making these items are found:

1. Decision-maker is the person or group of persons to choose the optimal variant out of the possible ones. If the issues are complex the decision is made by a group of people, and in case of current decisions, operational decisions are made by one person. The quality of decisions depends on the qualities, knowledge and skills of the decision-maker.

2. Decisional problem. The decision is made to solve a decision problem. In the absence of a problem the decision is irrelevant.

3. The number of decision variants can be finite or infinite. It includes all possibilities of solving the decision problem. In order to define this number, information within and outside the organization, creative management thinking, expertise and research are required. When the decision-making problem has been identified, the decision-maker acknowledges the existence of several possible courses of action. He may have these alternatives by direct involvement or through other persons. Choosing the best variant is done according to a series of appropriate methods of mathematical model that characterizes the decisional situation.

4. The number of decision criteria includes a series of features based on which decision variants are evaluated and compared in order to adopt the most rational decision. The number of decision criteria is represented by the points of view of the decision-maker who isolates aspects of economic reality in the decision-making process. Criteria decision making is characterized by several levels, according to different variants and / or states of objective conditions. In a decisional situation, when taking into account several criteria there must be taken into consideration the possibility of division and clustering criteria as well as their interdependence. For example, profits can be split by product, subunits etc. Also, profits and costs can be grouped into an overall criterion which is profitability. Two criteria are independent if the setting of a target in terms of a criterion does not influence the establishment of another goal, in terms of the second criterion. The company's management can use criteria such as: turnover, price, quality, investment recovery period, the cycle of production, utilization of production capacity etc.

5. Environment (objective conditions) is represented by the total internal and external conditions that are influenced and influence the decision. For a given decisional situation, several states of objective conditions can occur in the environment. The environment is characterized by great mobility. In the internal conditions one can observe a perfecting of personnel training and improvement of information system, and in terms of external conditions, one can notice changes in legislation of the country and changes in business relationships with various organizations. Sometimes the evolution of the environment can be adversarial with regard to its influence on decision making process within the firm. Thus, the increasing complexity of business activity adversely affects the substantiation of decision, while raising the level of professional training and management training has favourable effects on decision making.

6. The number of consequences includes all the results that would be obtained according to each decision criteria and each state of objective conditions by applying variants of decision. Establishing consequences is an activity that is not always done accurately because the causes that would determine their appearance are not known with certainty. The consequences may affect the quantity or the quality.

7. Objectives are levels of decision by the governor proposed to be achieved following the implementation of decision variant chosen. 
8. The utility of each consequence of the different variants is expressed in the same unit of measure that varies between 0 and 1, the utility representing the governor's expected benefit from the fact that a certain consequence is achieved.

9. Information - an essential element in decision-making

The importance of information and information systems has been synthesized by J. Naisbitt as the result of a calculation which tried to determine the percentage of the U.S. workforce directly involved in the creation, use or distribution of information. Considering that the study was conducted in the early 80 's the results are impressive, even for the U.S. - the percentage of so-called knowledge workers proved to be about $70 \%$ of the total. The development of information technology led to the inclusion of information as the sixth organizational resource, along with human resources, machinery, financial resources, materials and management. Even in terms of inviolability, the information is a highly efficient and economical way to reunite other business resources. In addition, information is used both to assist the other five organizational resources in coordinating activities and to plan, route and control these activities. In this context, building systems responsible for assisting the decision arises as a priority for the new wave of managers. In a ranking of the importance of resources in terms of management, the second after the human factor is the quality and frequency of business information. Now, even if the information is no longer undervalued, underestimated and under-utilized as in previous years, there are a number of issues related to its use in decision-making process. Generally, these issues relate to quality and value of information, the volume of information sent to managers and their periodicity.

a. The quality and value of information

In an ideal situation managers should be able to define the type of information they need, and the management information system should be able to offer it to them. In practice, however, this is not always possible. According to Peter Drucker, "Most decisions should be based on incomplete knowledge either because the information is not available, or because it would cost too much time and money to obtain it". However, to make the right decision, managers must have the relevant information that will increase knowledge, reduce uncertainty, and is useful for their intended purpose. Extremely important for managers is also information value, value derived from changes in decision behaviour caused by data availability. When estimating the information, the cost of producing that particular information should also be taken into account. Thus, acquiring, handling, recording and processing data, regardless of the means used for this, do not produce value but only involve cost. Value appears only when the data is communicated and understood by the recipient thereby transforming into information. In evaluating the information in terms of value created, its user has the main role and the second factor in this evaluation is how that information is used to improve decision making. Quality information is that information which creates value through use and is characterized by the following elements: it is relevant to the purpose or it is sufficiently accurate for its purpose, complete enough for the problem it refers to, it comes from a reliable source, one that the User trusts, it is communicated in time for the purpose, it is properly detailed, it is communicated through an appropriate channel and it is understood by the user.

b. The amount and frequency of information

Another major problem that managers are facing is the large amount of information. A large volume of information can cause not only strangulation and agglomerations in the system but it may also prevent managers from fulfilling their tasks. Previous computer systems contained a large number of data, but it was turned into information only when it was involved in assisting the decision process. Unfortunately, much too often data is often confused with information which leads to situations in which managers are forced to make important decisions in the absence of relevant information. Planning and a good control of operations through effective decision should be based on a constant flow of quality information in real time. Data must be processed and sent to the appropriate recipient in due time so that the entire operational environment can be changed or controlled. 
Under these circumstances and given the accelerated pace of business the need to use a computer system to assist managers emerges. The system should not interfere with managers' rational judgement, but it must increase their abilities and become an extension of managers' judgement. In conclusion, the information needs to meet the following requirements in order to be used by an organization as a sixth resource:

1. Ro respond quickly to changing competitive conditions; in this way new opportunities can be taken more quickly and vulnerable competitive points can be reduced;

2. To increase effectively the organization's internal productivity with a stress on managers' productivity; this requires better coordination of the functional elements of the organization.

3. To improve creativity, productivity and effectiveness of individual and group decisionmakers within the organization; this means providing appropriate tools to collect real and timely information, improving information analysis and quality decisions, as well as dispatching, assisting and monitoring the implementation of management actions and decisions. These three conditions are required to obtain information that will provide certainty of obtaining competitive advantage for the organization and improvement of management productivity.

\section{References}

1. Avornicului C. Avornicului M., (2007), Management and systems design, Cluj-Napoca, Romania, Risoprint;

2. Gherguț A., (2007), General and Strategic Management in Education, Iasi, Romania, Polirom;

3. Mallach, EG, (2000), Decision Support and Data Warehouse Systems, Boston, USA, McGraw-Hill Irwin;

4. Niculescu O.,(2001), Information systems of management organization, Economic Publishing House; 2001;

5. D. Oprea, Dumitru F., Mesnic G., (2005), Systems analysis, Ed Univ. "Al. Ioan Cuza ", Iasi, Romania;

6. Roger, I Ursăcescu, M, Vlădean, D. Knock, M, Burlacu S., (2007), Informatics and Management, Bucharest, Romania, University Publishing House ;

7. Rosca I., (2006), Computer-information society. E-Services, Publishing House, Bucharest, Romana, Publishing House;

8. Toca I., (2002), Educational management, Bucharest, Romania, Didactic and Pedagogical Publishing House;

9. Zacharias, D., (2001), Information systems to assist decision, Bucharest, Romania, Dual Tech. 